\title{
Analysis of porcine MUC4 gene as a candidate gene for prolificacy QTL on SSC13 in an Iberian $\times$ Meishan $\mathrm{F}_{2}$ population
}

Ingrid Balcells ${ }^{1 *}$, Anna Castelló ${ }^{1}$, Anna Mercadé ${ }^{2}$, José L Noguera ${ }^{3}$, Amanda Fernández-Rodríguez $^{4}$, Armand Sànchez ${ }^{1,2}$ and Anna Tomàs ${ }^{5}$

\begin{abstract}
Background: Reproductive traits, such as prolificacy, are of great interest to the pig industry. Better understanding of their genetic architecture should help to increase the efficiency of pig productivity through the implementation of marker assisted selection (MAS) programmes.

Results: The Mucin 4 (MUC4) gene has been evaluated as a candidate gene for a prolificacy QTL described in an Iberian $\times$ Meishan $(\mathrm{Ib} \times \mathrm{Me}) \mathrm{F}_{2}$ intercross. For association analyses, two previously described SNPs (DQ124298: g.243A>G and DQ124298:g.344A>G) were genotyped in 347 pigs from the $\mathrm{lb} \times$ Me population. QTL for the number of piglets born alive (NBA) and for the total number of piglets born (TNB) were confirmed on SSC13 at positions $44 \mathrm{cM}$ and $51 \mathrm{cM}$, respectively. The MUC4 gene was successfully located within the confidence intervals of both QTL. Only DQ124298:g.344A>G MUC4 polymorphism was significantly associated with both NBA and TNB $(P$-value $<0.05)$ with favourable effects coming from the Meishan origin. MUC4 expression level was determined in $\mathrm{F}_{2}$ sows displaying extreme phenotypes for the number of embryos (NE) at 30-32 days of gestation. Differences in the uterine expression of MUC4 were found between high (NE $\geq 13)$ and low (NE $\leq 11)$ prolificacy sows. Overall, MUC4 expression in high prolificacy sows was almost two-fold increased compared with low prolificacy sows.
\end{abstract}

Conclusions: Our data suggest that MUC4 could play an important role in the establishment of an optimal uterine environment that would increase embryonic survival during pig gestation.

\section{Background}

Prolificacy traits have been widely explored during the last decades as a potential tool for increasing efficiency of sow productivity in the pig industry. Genetic improvement programmes have achieved moderate gains in prolificacy related traits owing to their low heritability, late expression in life and sex limitation [1]. Increasing knowledge on the genetic architecture of prolificacy traits would provide new tools to improve the efficiency of genetic selection by implementing marker assisted selection (MAS).

So far a relatively low number of quantitative trait loci (QTL) for prolificacy traits reaching the genome-wide significance level have been identified [2,3]. The most significant QTL affecting the number of piglets born alive

\footnotetext{
* Correspondence: Ingrid.Balcells@uab.cat

'Departament de Genètica Animal, Centre de Recerca en Agrigenòmica

(CRAG), Universitat Autònoma de Barcelona, 08193 Bellaterra, Spain

Full list of author information is available at the end of the article
}

(NBA) and the total number of piglets born (TNB) were described by Noguera et al. [3] in the same resource population as used in the present study, an Iberian (Ib) by Meishan $(\mathrm{Me}) \mathrm{F}_{2}$ intercross. A number of epistatic QTL were also detected, thus indicating that the genetic architecture of reproductive traits is built as a complex network of interactions throughout the genome. Some of these epistatic QTL were further confirmed and putative candidate interacting genes were identified [4].

Porcine chromosome 13 (SSC13) harbours the most significant QTL for TNB and NBA [3]. The Mucin 4 (MUC4) gene is located within the confidence interval of prolificacy QTL. Mucins are large heterodimeric glycoproteins commonly located on apical surfaces of many wet-surfaced epithelia that play a key role in the lubrication and protection of the uterine mucosa [5-7]. They have been shown to present anti-adhesive and anti-recognition properties which are necessary to protect the endometrium from the 
binding and invasion of the trophoectoderm [8,9]. A role of MUC4 has been pointed out in rodents and pigs during pregnancy although its expression during the peri-implantational period varies depending on the type of implantation in each species. In mice and rats, which have an invasive type of implantation, MUC4 expression is downregulated to generate the receptive state for uterine implantation [8-12]. Conversely, in pigs, where a non-invasive epitheliochorial placental attachment takes place, MUC4 is upregulated in the uterus [13]. A protective role has been suggested for $M U C 4$ owing to the fact that it is localized on the endometrium epithelium blocking the access of different substrates to the cell surface [14]. The endometrium is then protected from proteolytic activity of porcine conceptus [13] and from microbial invasion [15] resulting in better uterine conditions for embryo development. In pigs, the disruption of the uterine microenvironment could affect embryo viability which could lead to prenatal mortality rates ranging from 20 to $46 \%$ [16]. The improvement of the uterine microenvironment would increase embryonic survival and, in consequence, the number of piglets born alive.

In humans, polymorphisms in the $M U C 4$ nucleotide sequence have been significantly associated with the development of endometriosis and endometriosis related infertility [17]. However, no association with implantation failure has been detected [18]. In livestock species, the genetic association of MUC4 gene variants with reproductive traits has not yet been explored. In pigs, polymorphisms in the MUC4 gene were shown to be in linkage disequilibrium with susceptibility/resistance to Enterotoxigenic Escherichia coli (ETEC) F4ab/ac infection [19].

In the current study, we have examined the porcine $M U C 4$ gene as a functional and positional candidate gene to explain the prolificacy QTL previously identified on $\mathrm{SSC} 13$ in the Ib $\times$ Me population [3].

\section{Results}

\section{Refinement of SSC13 QTL for NBA and TNB}

The resulting linkage map for SSC13 in the $\mathrm{Ib} \times \mathrm{Me}$ population was as follows (distance is indicated in centimorgan (cM)): S0076 (0.0) - ITIH3 (18.7) - SWR1008 (27.5) MUC4 (39.1) - SW398 (55.8) - SW2440 (78.5) - SW769 (91.5). The position of the MUC4 gene is in agreement with the pig genome sequence (Sus scrofa, Ensembl release 64 - September 2011).

A single QTL scan (model 1) was performed on SSC13 for TNB and NBA (Figure 1). As previously described by Noguera et al. [3], two significant QTL for NBA and for TNB were identified at positions $44 \mathrm{cM}$ and $51 \mathrm{cM}$, respectively (Table 1 ). Significant additive effects were detected for both QTL which determined an increase of $0.65 \pm 0.22$ piglets per copy for NBA and $0.51 \pm 0.22$ for

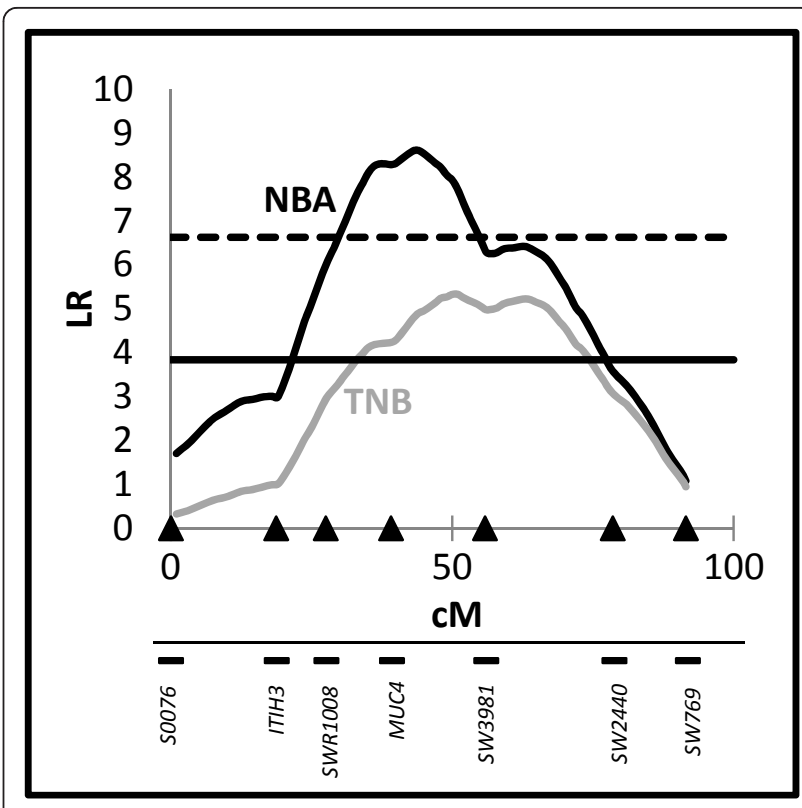

Figure 1 QTL profiles on SSC13 for NBA and TNB showing the likelihood ratio test statistic. The horizontal lines set at 3.84 and 6.63 show the 0.05 and the 0.01 significance levels respectively.

TNB. It is noteworthy that the MUC4 gene was mapped within the confidence interval (CI) of both QTL.

\section{Candidate gene association analyses}

Allele frequencies for DQ124298:g.243A $>G$ and DQ124298:g.344A>G SNPs in the $\mathrm{Ib} \times$ Me population are shown in Table 2. Associations between MUC4 polymorphisms and reproductive traits were tested with a standard animal model (model 2). No significant associations were found for the DQ124298:g.243A>G SNP and the reproductive traits recorded (data not shown). For the DQ124298:g.344A>G SNP, the results supported significant additive effects between this SNP and NBA and TNB traits $(P$-value $<0.05$, Table 1$)$. The additive substitution effect for DQ124298:g.344G SNP was estimated to be $0.74 \pm 0.27$ for NBA (P-value $=0.006)$ and $0.57 \pm 0.27$ for TNB $(P$-value $=0.037)$. In both cases, the $\mathrm{G}$ allele coming from the Me breed had a favourable effect. Note that DQ124298:g.344A>G SNP had a larger effect on NBA than on TNB $(P$-value $=0.006$ for NBA and $P$ value $=0.037$ for $\mathrm{TNB})$.

The results obtained with association studies must be interpreted with caution due to the fact that the extensive linkage disequilibrium described in $\mathrm{F}_{2}$ crosses can bias the estimations. For this reason, in order to detect possible false positives obtained in association studies with DQ124298:g.344A>G SNP, a marker assisted association test (MAAT) including the QTL effect in the association test [20] was performed with model 3. Results from the 
Table 1 Results of QTL analyses, association tests and marker assisted association tests for prolificacy traits

\begin{tabular}{|c|c|c|c|c|c|c|c|c|c|}
\hline \multirow[b]{2}{*}{ Trait } & \multicolumn{3}{|c|}{ QTL model (model 1) } & \multicolumn{2}{|c|}{ MUC4 association (model 2) } & \multicolumn{4}{|c|}{ QTL + MUC4 association model (model 3) ${ }^{1}$} \\
\hline & Pos. $(c . i)^{2}$ & P-QTL & $\mathrm{a}_{\mathrm{QTL}}(\mathrm{SE})^{3}$ & P-MUC4 & $a_{\text {MUC4 }}(\mathrm{SE})^{4}$ & Pos. $^{5}$ & 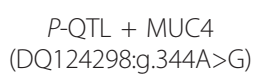 & P-QTL & 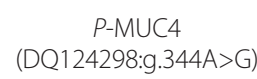 \\
\hline NBA & $44(22-77)$ & 0.003 & $0.65(0.22)$ & 0.006 & $0.74(0.27)$ & 63 & 0.003 & 0.062 & 0.007 \\
\hline TNB & $51(33-74)$ & 0.021 & $0.51(0.22)$ & 0.037 & $0.57(0.27)$ & 64 & 0.019 & 0.061 & 0.039 \\
\hline
\end{tabular}

${ }^{1} P$-values obtained with the model that includes the QTL and the DQ124298:g.344A>G MUC4 SNP effects; each effect(s) was tested by removing it from the null model; ${ }^{2} \mathrm{QTL}$ position (in CM); c.i = confidence interval; ${ }^{3} \mathrm{QTL}$ additive effect; SE = standard error; ${ }^{4} \mathrm{DQ} 124298: \mathrm{g} .344 \mathrm{~A}>\mathrm{G}$ MUC4 SNP additive effect; ${ }^{5} \mathrm{QTL}$ position in cM when corrected by the DQ124298:g.344A>G MUC4 SNP effect.

MAAT are summarized in Table 1. The DQ124298: g.344A $>$ G SNP effect on NBA and TNB remained significant when the QTL effect was considered which is in agreement with the association studies analyses. Nevertheless, the significance of the QTL disappeared when the DQ124298:g.344A>G SNP was included in the model. MAAT shows that the DQ124298:g.344A>G SNP genotype explains better the effects on NBA and TNB and confirms the association detected with model 2.

\section{Expression analysis of the porcine MUC4 gene}

In order to determine whether MUC4 expression could affect prolificacy related traits, we analysed the uterine expression profile of porcine MUC4 in sows that differed in the number of embryos (NE) at 30-32 days of gestation using qPCR. At this time of gestation, the embryo is already attached to the endometrium and the foetal survival rate will be an indication of the final litter size [1]. For this reason, NE was measured as an estimation of prolificacy. Results showed that mRNA expression levels of MUC4 gene were suggestively greater in high ( $\mathrm{NE} \geq 13$, $\mathrm{n}=16$, mean relative expression $=7.22)$ than in low $(\mathrm{NE} \leq$ $11, \mathrm{n}=20$, mean relative expression $=3.63$ ) prolificacy sows $(P$-value $=0.07$, Figure 2$)$, reaching almost a two-fold increase in the high prolificacy group.

\section{Discussion}

Statistical association between the DQ124298:g.344A>G mutation in the porcine MUC4 gene and prolificacy related traits has been reported. No association was found, however, between the DQ124298:g.243A>G SNP and the

Table 2 Allelic frequencies of the DQ124298:g.243A>G and DQ124298:g.344A>G MUC4 polymorphisms in the $\mathrm{Me} \times \mathrm{Ib} \mathrm{F}_{2}$ population

\begin{tabular}{|c|c|c|c|c|c|c|c|}
\hline & & \multicolumn{3}{|c|}{ DQ124298:g.243 } & \multicolumn{3}{|c|}{ DQ124298:g.344 } \\
\hline & & n & A & G & $\mathbf{n}$ & A & G \\
\hline \multirow[t]{4}{*}{$F_{0}$} & Q Meishan & 18 & 0 & 1 & 18 & 0 & 1 \\
\hline & o' Iberian & 3 & 0.50 & 0.50 & 3 & 0.50 & 0.50 \\
\hline & $F_{1}$ & 120 & 0.32 & 0.68 & 123 & 0.18 & 0.82 \\
\hline & $\mathrm{F}_{2}$ & 206 & 0.20 & 0.80 & 202 & 0.29 & 0.71 \\
\hline
\end{tabular}

prolificacy related traits although this SNP is located 100bp upstream of the DQ124298:g.344A>G mutation. The difference in association analysis detected between both MUC4 SNPs indicates that they are not in linkage disequilibrium. The MUC4 gene successfully mapped within the confidence interval of the SSC13 QTL affecting NBA and TNB traits previously described by Noguera et al. [3] using the same resource population. The favourable effect of DQ124298:g.344A>G SNP was inherited from the Me maternal breed, as expected, since Me is more prolific than Ib. The effect of the DQ124298:g.344A>G MUC4. SNP was stronger for NBA than for TNB suggesting that the MUC4 gene could be related to the embryonic survival in the uterus. This hypothesis is supported by the differential expression of the MUC4 gene found in the uterus at 30-32 days of gestation, where the expression was twofold higher in high than in low prolificacy sows. Nevertheless, further studies must be performed in other unrelated porcine populations to validate the association which was obtained in this study.

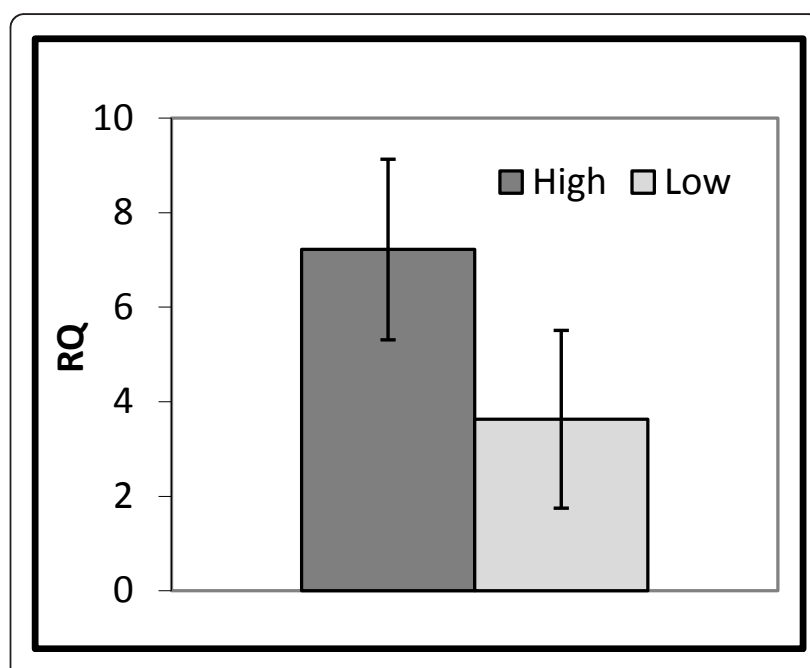

Figure 2 Relative quantification (RQ) of the porcine MUC4 gene in the uterus. MUC4 expression in the uterus was measured in 36 $\mathrm{F}_{2}$ sows that were classified into two groups according to the number of embryos (NE) at the sacrifice day (30-32 days of gestation): low (NE $\leq 11)$ and high $(N E \geq 13)$. 
MUC4 has been identified as a potential regulator of placentation in pigs [21]. In porcine uterine surface epithelium, MUC4 gene expression increases during the first 18 days of gestation [13] whereas in rats a reduction in MUC4 gene expression in the uterus is associated with the period of implantation [12]. Differences in $M U C 4$ expression profiles could be explained by the different placentation types of rodents and pigs. Pigs have a noninvasive type of placentation and MUC4 is thought to play a role in protecting the uterus from erosion by the embryo $[13,15]$. MUC4 and MUC1 are the major mucin proteins expressed in the endometrial epithelium [22,23]. Human MUC1 and MUC4 present highly polymorphic sites with a variable number of tandem repeats (VNTRs). MUC1 VNTR variants have been related to alterations in both $\mathrm{T}$-antigen presentation and in the local immune response in cancer $[17,24,25]$. These results suggest that mucins may play a role in the immunological processes that take place during the implantation period essential to ensure the correct establishment of maternal-foetal tolerance [26].

\section{Conclusions}

MUC4 polymorphism DQ124298:g.344A $>\mathrm{G}$ is associated with litter size in the $\mathrm{Ib} \times \mathrm{Me}$ population and, moreover, MUC4 is differentially expressed regarding the number of embryos in uterus at 30 days of gestation. These results suggest that MUC4 may participate in the establishment of an optimal uterine environment essential for adequate embryo development during the early stages of gestation and increase litter size in pigs.

\section{Methods}

Animal material and phenotypic measurements

An $\mathrm{F}_{2}$ population was generated by crossing $3 \mathrm{Ib}$ males from the Guadyerbas line (Dehesón del Encinar, Toledo, Spain) with 18 Me females (Domaine du Magneraud, INRA, France). A total of 8 boars and 97 sows from the $F_{1}$ generation were mated to obtain the $F_{2}$ progeny in the Nova Genètica S.A experimental farm (Lleida, Spain). All animals were obtained according to the European animal experimentation ethics law approved by the Ethical and Care Committee at IRTA.

Measurements of sow reproduction traits including TNB and NBA were recorded in $255 \mathrm{~F}_{2}$ sows during 4 successive parities. In the fifth parity, sows were slaughtered at 30-32 days of gestation, when the uterus samples were recollected and the number of embryos (NE) was recorded.

\section{Genotyping of MUC4 polymorphisms}

Two MUC4 polymorphisms described by [19], two A-toG substitution polymorphisms at positions 243 and 344 of intron 17 (GenBank accesion number DQ124298), were genotyped in our Ib $\times$ Me population by pyrosequencing [27] in a PSQ HS 96 system (Pyrosequencing AB, Uppsala, Sweden). Two PCR amplifications, one for each SNP, were carried out in a $25 \mu \mathrm{l}$ total volume that included $1.5 \mathrm{mM}$ of $\mathrm{MgCl}_{2}, 200 \mu \mathrm{M}$ of each dNTP, 0.75 $\mathrm{U}$ of TaqGold DNA polymerase (Applied Biosystems), $320 \mathrm{nM}$ of each primer (Table 3 ) and $40 \mathrm{ng}$ of DNA. The thermal profile was $95^{\circ} \mathrm{C}$ for $10 \mathrm{~min}, 40$ cycles at $94^{\circ} \mathrm{C}$ for $30 \mathrm{~s}, 58^{\circ} \mathrm{C}$ for $45 \mathrm{~s}$ and $72^{\circ} \mathrm{C}$ for $1 \mathrm{~min}$ and a final extension step of $15 \mathrm{~min}$ at $72^{\circ} \mathrm{C}$. A multiplex pyrosequencing reaction was performed with $5 \mu \mathrm{l}$ of each PCR with the primers described in Table 3.

\section{QTL and association analyses}

The linkage map of porcine chromosome 13 (SSC13) was constructed with the Build option of CRIMAP 2.4 software [28]. Overall, seven markers were used: five microsatellites that had been previously described by [3], one SNP at the ITIH3 gene (dbSNP accession number ss315834911) and the DQ124298:g.344A>G MUC4 SNP described by [19].

Three models were used to analyse the $\mathrm{Ib} \times \mathrm{Me} \mathrm{F}_{2}$ population data: (1) a QTL model, (2) an association model and (3) a QTL + association model to perform the marker assisted association test (MAAT) proposed by [20].

First, one dimensional QTL mapping was performed with model 1 .

$$
y_{i j k}=H_{i}+O_{j}+u_{k}+p_{k}+C_{a} a+e_{i j k l} \quad(\text { model } 1)
$$

where $y_{i j k}$ was the phenotypic data vector for NBA or TNB; $H_{i}$ and $O_{j}$ were the fixed effects for year-season and parturition order, respectively; $u_{k}$ was the random polygenic effect of each individual; $p_{k}$ was the environmental permanent effect of the sow; $a$ was the QTL additive effect; $C_{a}$ was the probability of the individual being homozygous for Ib alleles minus the probability of being homozygous for Me alleles at the QTL position of interest; and $e_{i j k l}$ was the random residual term. The dominance effect was not included in the model because the likelihood ratio test performed indicated that a model with only additive QTL effect fitted better.

Second, association analyses were performed with the MUC4 SNPs (DQ124298:g.243A>G and DQ124298: g.344A $>$ G) with a standard animal model (model 2).

$$
y_{i j k}=H_{i}+O_{j}+u_{k}+p_{k}+\sum_{k} \lambda_{i k} a_{k}+e_{i j k l} \quad \text { (model 2) }
$$

where $y_{i j k}$ was the vector containing the phenotypic data for NBA and TNB and $\lambda_{i k}$ was a variable that indicated the number of copies $(0,1$, or 2$)$ of the $k^{\text {th }}$ allele presented by each individual.

Finally, a combined QTL + association model (model 3) was used to consider the extensive linkage disequilibrium 
Table 3 List of primer sequences used for typing MUC4 polymorphisms and quantitative PCR

\begin{tabular}{|c|c|c|c|}
\hline Application & SNP/Gene & Primer Sequence $\left(5^{\prime} \rightarrow 3^{\prime}\right)$ & Length (bp) \\
\hline \multirow{6}{*}{$\begin{array}{c}\text { Pyrosequencing } \\
\text { PCR }\end{array}$} & DQ124298:g.243A>G & F:*tggtgctacccccagatttg & 195 \\
\hline & & R:gttgtgtccaccccttacccttat & \\
\hline & & P:gtcccctctcccaggta & \\
\hline & DQ124298:g.344A>G & F:*gtggecctcagtcactagagt & 258 \\
\hline & & R:cgaagttgtgaaaggaagacag & \\
\hline & & P:ttggggttggggcag & \\
\hline \multirow[t]{2}{*}{ qPCR } & MUC4 & F:atgggcttctccagtggagat & 66 \\
\hline & & R:tctcccacactggctgcaa & \\
\hline
\end{tabular}

* $5^{\prime}$ Biotin labelled, $\mathrm{F}$ forward primer, $\mathrm{R}$ reverse primer, $\mathrm{P}$ pyrosequencing primer

present in $F_{2}$ population. Only the DQ124298:g.344A>G SNP was considered because significant results were obtained in model 2.

$$
y_{i j k}=H_{i}+O_{j}+u_{k}+p_{k}+C_{a} a+\sum_{k} \lambda_{i k} a_{k}+e_{i j k l} \quad \text { (model 3) }
$$

All analyses were performed with Qxpack software [29]. QTL scans were analysed every $\mathrm{cM}$ and nominal P-values were calculated with the maximum likelihood ratio test, assuming a $\chi^{2}$ distribution of the likelihood ratio test with degrees of freedom calculated as the difference between the number of parameters in the alternative and in the null models.

\section{Expression analysis of the MUC4 gene}

Uterine expression of the MUC4 gene was measured by reverse transcription quantitative real time PCR (RTqPCR). Total RNA from uterus samples was extracted by means of the RiboPure ${ }^{\mathrm{TM}}$ kit (Ambion, Applied Biosystems). One microgram of total RNA in $40 \mu \mathrm{l}$ reaction was reverse transcribed with the High Capacity cDNA Transcription Kit (Applied Biosystems). Primers for MUC4 (Table 3) were designed with Primer Express ${ }^{\circledR} 2.0$ software (Applied Biosystems, Warrington, UK). Sus scrofa hypoxanthine phosphoribosyltransferase 1 (HPRT1) was used as a reference gene for normalization [for primer sequences see 30]. qPCR reactions were performed in triplicate in a $20 \mu \mathrm{l}$ final volume including $2 \mathrm{X}$ FastStart SYBR Green Master (Roche), $0.3 \mu \mathrm{M}$ of each primer and $5 \mu \mathrm{l}$ of the cDNA diluted twenty times on an ABI PRISM ${ }^{\circledR} 7900 \mathrm{HT}$ sequence detection system (Applied Biosystems, Warrington, UK). Thermal conditions were $95^{\circ} \mathrm{C}$ for $10 \mathrm{~min}$ followed by 40 cycles of $95^{\circ} \mathrm{C}$ for $15 \mathrm{~s}$ and $60^{\circ} \mathrm{C}$ for $1 \mathrm{~min}$. Dissociation curve analyses were performed in order to detect unspecific amplifications. PCR efficiencies of MUC4 and HPRT1 genes were calculated to validate the use of the $2^{-\Delta \Delta C t}$ method [31]. The MUC4 gene expression level was measured individually in $36 \mathrm{Ib} \times \mathrm{Me} \mathrm{F}_{2}$ sows from 32 different litters that were classified into two groups according to the NE at slaughter (30-32 days of pregnancy): low $(\mathrm{NE} \leq 11, \mathrm{n}=20)$ and high $(\mathrm{NE} \geq 13, \mathrm{n}=16)$. Gene expression data were $\log _{10}$ transformed and analysed by a t-test using the Statistical Analysis System (Statistics, V 9.1.3; SAS Institute, Inc., Cary, NC). The significance threshold was set at $\alpha<0.05$.

\section{Acknowledgements}

The authors are indebted to L. Varona, M. Arqué, J. Tarrés, M. Fina, and the staff of Nova Genètica, particularly E. Ramells, F. Márquez, R. Malé, F. Rovira, and I. Riart, for cooperating in the experimental protocol. The authors gratefully acknowledge the contributions of the INRA (France) and the CIA EI Dehesón del Encinar (Spain) in providing the purebred Meishan sows and Iberian boars, respectively. The authors also thank J. Casellas, V. Martínez and S. Cirera for critical comments on the manuscript. This research was funded in part by Project AGL2004-08368-C03 and by the Consolider-Ingenio 2010 Programme (CSD2007-00036), both from the Spanish Ministry of Science and Innovation. IB is the recipient of a PIF PhD fellowship from Universitat Autònoma de Barcelona.

\section{Author details}

'Departament de Genètica Animal, Centre de Recerca en Agrigenòmica (CRAG), Universitat Autònoma de Barcelona, 08193 Bellaterra, Spain. ${ }^{2}$ Servei Veterinari de Genètica Molecular, Universitat Autònoma de Barcelona, 08193 Bellaterra, Spain. ${ }^{3}$ Genètica i Millora Animal, IRTA-Lleida, 25198 Lleida, Spain. ${ }^{4}$ Departamento de Mejora Genética Animal, SGIT-INIA, 28040 Madrid, Spain. ${ }^{5}$ Program Infection and Immunity, FISIB, 07110 Bunyola, Spain.

\section{Authors' contributions}

IB carried out GPCR experiments, analysed and interpreted the data and prepared the manuscript. AC performed the genotyping task and revised the manuscript. AM designed the genotyping protocol. JLN participated in the design of the study and coordinated it. AF participated in sample collection and helped with the critical revision of the manuscript. AS conceived the study, participated in the design and the supervision of the study and revised the draft. AT supervised the study, helped to draft the manuscript and revised it. All authors read and approved the final manuscript.

Received: 4 July 2011 Accepted: 31 October 2011

Published: 31 October 2011

\section{References}

1. Spotter A, Distl O: Genetic approaches to the improvement of fertility traits in the pig. Vet J 2006, 172:234-247.

2. Tribout T, lannuccelli N, Druet T, Gilbert H, Riquet J, Gueblez R, Mercat MJ, Bidanel JP, Milan D, Le Roy P: Detection of quantitative trait loci for reproduction and production traits in Large White and French Landrace pig populations. Genet Sel Evol 2008, 40:61-78. 
3. Noguera $J$, Rodriguez C, Varona L, Tomas A, Munoz G, Ramirez O, Barragan C, Arque M, Bidanel JP, Amills M, Ovilo C, Sanchez A: A bidimensional genome scan for prolificacy traits in pigs shows the existence of multiple epistatic QTL. BMC Genomics 2009, 10:636.

4. Fernandez-Rodriguez A, Rodriguez C, Varona L, Balcells I, Noguera JL, Ovilo C, Fernandez Al: Analysis of candidate genes underlying two epistatic quantitative trait loci on SSC12 affecting litter size in pig. Anim Genet 2010, 41:73-80.

5. Moniaux N, Nollet S, Porchet N, Degand P, Laine A, Aubert JP: Complete sequence of the human mucin MUC4: a putative cell membraneassociated mucin. Biochem J 1999, 338:325-333.

6. Lagow E, DeSouza MM, Carson DD: Mammalian reproductive tract mucins. Hum Reprod Update 1999, 5:280-292.

7. Govindarajan B, Gipson IK: Membrane-tethered mucins have multiple functions on the ocular surface. Exp Eye Res 2010, 90:655-663.

8. McNeer RR, Carraway CA, Fregien NL, Carraway KL: Characterization of the expression and steroid hormone control of sialomucin complex in the rat uterus: implications for uterine receptivity. J Cell Physiol 1998, 176:110-119.

9. McNeer RR, Huang D, Fregien NL, Carraway $\mathrm{KL}$ : Sialomucin complex in the rat respiratory tract: a model for its role in epithelial protection. Biochem J 1998, 330:737-744.

10. Idris N, Carraway KL: Sialomucin complex (Muc4) expression in the rat female reproductive tract. Biol Reprod 1999, 61:1431-1438.

11. Idris N, Carraway KL: Regulation of sialomucin complex/Muc4 expression in rat uterine luminal epithelial cells by transforming growth factor-beta: implications for blastocyst implantation. J Cell Physiol 2000, 185:310-316.

12. Carraway $\mathrm{KL}$, Idris $\mathrm{N}$ : Regulation of sialomucin complex/Muc4 in the female rat reproductive tract. Biochem Soc Trans 2001, 29:162-166.

13. Ferrell AD, Malayer JR, Carraway KL, Geisert RD: Sialomucin complex (Muc4) expression in porcine endometrium during the oestrous cycle and early pregnancy. Reprod Domest Anim 2003, 38:63-65.

14. Komatsu M, Carraway CA, Fregien NL, Carraway KL: Reversible disruption of cell-matrix and cell-cell interactions by overexpression of sialomucin complex. J Biol Chem 1997, 272:33245-33254.

15. Carraway KL, Perez A, Idris N, Jepson S, Arango M, Komatsu M, Haq B, PriceSchiavi SA, Zhang J, Carraway CA: Muc4/sialomucin complex, the intramembrane ErbB2 ligand, in cancer and epithelia: to protect and to survive. Prog Nucleic Acid Res Mol Biol 2002, 71:149-185.

16. Ross JW, Ashworth MD, Stein DR, Couture OP, Tuggle CK, Geisert RD: Identification of differential gene expression during porcine conceptus rapid trophoblastic elongation and attachment to uterine luminal epithelium. Physio/ Genomics 2009, 36:140-148.

17. Chang CY, Chang HW, Chen CM, Lin CY, Chen CP, Lai CH, Lin WY, Liu HP, Sheu JJ, Tsai FJ: MUC4 gene polymorphisms associate with endometriosis development and endometriosis-related infertility. BMC Med 2011, 9:19.

18. Koscinski I, Viville S, Porchet N, Bernigaud A, Escande F, Defossez A, Buisine MP: MUC4 gene polymorphism and expression in women with implantation failure. Hum Reprod 2006, 21:2238-2245.

19. Peng QL, Ren J, Yan XM, Huang X, Tang H, Wang YZ, Zhang B, Huang LS: The g.243A>G mutation in intron 17 of MUC4 is significantly associated with susceptibility/resistance to ETEC F4ab/ac infection in pigs. Anim Genet 2007, 38:397-400.

20. Zhao H, Rothschild MF, Fernando RL, Dekkers JC: Tests of candidate genes in breed cross populations for QTL mapping in livestock. Mamm Genome 2003, 14:472-482.

21. Ostrup E, Bauersachs S, Blum H, Wolf E, Hyttel P: Differential endometrial gene expression in pregnant and nonpregnant sows. Biol Reprod 2010, 83:277-285.

22. Gollub EG, Goswami S, Kouba D, Marom Z: Regulation of mucin gene expression in secretory epithelial cells. Biochem Biophys Res Commun 1993, 197:667-673.

23. Audie JP, Tetaert D, Pigny P, Buisine MP, Janin A, Aubert JP, Porchet N, Boersma A: Mucin gene expression in the human endocervix. Hum Reprod 1995, 10:98-102.

24. Fowler JC, Teixeira AS, Vinall LE, Swallow DM: Hypervariability of the membrane-associated mucin and cancer marker MUC1. Hum Genet 2003, 113:473-479.

25. Santos-Silva F, Fonseca A, Caffrey T, Carvalho F, Mesquita P, Reis C, Almeida R, David L, Hollingsworth MA: Thomsen-Friedenreich antigen expression in gastric carcinomas is associated with MUC1 mucin VNTR polymorphism. Glycobiology 2005, 15:511-517.

26. Guerin LR, Prins JR, Robertson SA: Regulatory T-cells and immune tolerance in pregnancy: a new target for infertility treatment? Hum Reprod Update 2009, 15:517-535.

27. Ronaghi $M$, Pettersson $B$, Uhlen $M$, Nyren P: PCR-introduced loop structure as primer in DNA sequencing. BioTechniques 1998, 25:876-8, 880-2, 884

28. Green P, Falls K, Crooks S: Documentation of CRI-MAP.[http://compgen. rutgers.edu/old/multimap/crimap/index.html].

29. Perez-Enciso M, Misztal I: Qxpak: a versatile mixed model application for genetical genomics and QTL analyses. Bioinformatics 2004, 20:2792-2798.

30. Fernandes LT, Tomas A, Bensaid A, Perez-Enciso M, Sibila M, Sanchez A, Segales J: Exploratory study on the transcriptional profile of pigs subclinically infected with porcine circovirus type 2. Anim Biotechnol 2009, 20:96-109.

31. Livak KJ, Schmittgen TD: Analysis of relative gene expression data using real-time quantitative PCR and the 2(-Delta Delta C(T)) Method. Methods 2001, 25:402-408.

doi:10.1186/1471-2156-12-93

Cite this article as: Balcells et al: Analysis of porcine MUC4 gene as a candidate gene for prolificacy QTL on SSC13 in an Iberian $\times$ Meishan $F_{2}$ population. BMC Genetics 2011 12:93.

\section{Submit your next manuscript to BioMed Central and take full advantage of:}

- Convenient online submission

- Thorough peer review

- No space constraints or color figure charges

- Immediate publication on acceptance

- Inclusion in PubMed, CAS, Scopus and Google Scholar

- Research which is freely available for redistribution

Submit your manuscript at www.biomedcentral.com/submit
C Biomed Central 